Vol. 22 N.1 de 2019 ISSN: 1516-8182

Recebimento: 03/07/2018

Aceite: 07/09/2018

DOI: $10.25059 / 2527-2594 /$ retratosdeassentamentos/2019.v22i1.330

\title{
Estudo exploratório sobre dinâmica do desmatamento em assentamentos localizados no território portal da Amazônia
}

\author{
Silvia Regina Starling Assad de Ávila ${ }^{1}$ \\ Mario Ávila ${ }^{2}$ \\ José Vicente Elias Bernardi ${ }^{3}$ \\ Antônio Felipe Couto Júnior ${ }^{4}$
}

\begin{abstract}
Resumo: Os assentamentos na Amazônia são fundamentais para a distribuição de terras, porém sua implementação ainda traz muitos problemas ambientais e sociais, o que tem levado a críticas sobre as condições de sustentabilidade dos mesmos e avaliar o impacto ambiental ocasionado por este grupo local, está se tornando um dos empregos mais frequentes da utilização de indicadores. O objetivo deste texto então, foi caracterizar de maneira exploratória, a dinâmica do desmatamento em assentamentos localizados no Território Portal da Amazônia, localizado no norte do estado do Mato Grosso utilizando indicadores extraídos do IBGE, IMAZON e INPE. Neste estudo, os assentamentos que respondem por parcelas significativas de desmatamento estão nos municípios de Guarantã do Norte, Novo Mundo e Peixoto de Azevedo estando evidente a dinâmica de desmatamento ocasionado pela ocupação para pastagens, criação de bovinos seguido de culturas anuais (soja) em regiões selecionadas e migração para novas áreas para reiniciar o ciclo apresentado. Entender a dinâmica do desmatamento nos assentamentos localizados no Território Portal da Amazônia é essencial para que se busque implementar talvez, um modelo mais sustentável - capaz de conciliar a conservação da floresta e ainda melhorar a condição de vida dos assentados - bem como reduzir conflitos e pobreza rural.
\end{abstract}

Palavras-chave: Desmatamento; assentamentos de reforma agraria; Mato Grosso.

ABSTRACT: The Amazon settlements are fundamental for land distribution, but its implementation still brings many environmental and social problems, which has been criticized about its sustainability conditions. Evaluate the environmental impact caused by this local group, is becoming one of the most frequent jobs in the use of indicators. The objective of this text was to characterize in an exploratory way, the dynamics of deforestation in settlements located in the Territorio Portal da Amazonia, located in the north of the state of Mato Grosso using indicators extracted from IBGE, IMAZON and INPE . In this study, the settlements that account for significant portions of deforestation are in the municipalities of Guarantã do Norte, Novo Mundo and Peixoto de Azevedo being evident the dynamics of deforestation caused by the occupation for pastures, livestock breeding followed by annual crops (soybean) in selected regions and migration to new areas. Understanding

\footnotetext{
'Doutoranda em Ciencias ambientais - PPGCA/UnB. E-mail: silassad@gmail.com

${ }^{2}$ Doutor em Desenvolvimento Sustentavel - CDS/UnB. E-mail: unbavila@gmail.com

${ }^{3}$ Docentte do Programa de Pós-Graduação Interunidades (CENA-ESALQ) em Ecologia Aplicada, USP. E-mail: vicente. bernardi@yahoo.com.br

${ }^{4}$ Doutor em Geociências Aplicadas (2012) pelo Instituto de Geociências da Universidade de Brasília (UnB).E-mail: afcj@ unb.br
} 
the dynamics of deforestation in the settlements located in the Portal is essential to be sought to implement perhaps a more sustainable model-able to reconcile the forest conservation and still improve the settlers living condition as well as reducing conflicts and rural poverty.

KeYwords: Deforestation; Agrarian reform settlements; Mato Grosso.

\section{INTRODUÇÃo}

Os assentamentos na Amazônia são fundamentais para a distribuição de terras, porém sua implementação ainda traz muitos problemas ambientais e sociais, o que tem levado a críticas sobre as condições de sustentabilidade dos mesmos. Dados apontam por exemplo, que os assentamentos são responsáveis por parcela significativa do desmatamento no bioma amazônico. Segundo o IPAM (2016) no ano de 2016 o fenômeno aconteceu prioritariamente em terras privadas $(35,4 \%)$, seguidas por assentamentos $(28,6 \%)$ e terras públicas não destinadas e áreas sem informação cadastral (24\%).

Então, em se tratando dos assentamentos rurais, avaliar o impacto ambiental ocasionado por este grupo local, está se tornando um dos empregos mais frequentes da utilização de indicadores. Em 2009, Guimarães e Feichas discorrem sobre os desafios na construção de indicadores de sustentabilidade e, a partir de pesquisa bibliográfica analisaram cinco propostas de indicadores a fim de identificar alguns desafios a serem superados em sua construção, para que sejam capazes de promover mudanças de comportamentos e subsidiar decisões.

Alcorinte et al (2013) avaliaram as variáveis ambientais de assentamentos beneficiados pelos programas de reforma agrária da Região Central do estado de São Paulo utilizando métricas como Score Ambiental por unidade produtiva (SA) e Análise Individual de Variáveis (AI). Ainda em 2013, Leite Júnior et al (2013), buscaram - em três assentamentos de reforma agrária - localizados no Município de Goiás, mensurar a sustentabilidade dos assentamentos beneficiados pelos projetos de reforma agrária pelas políticas de governo federal e estadual considerando-se os aspectos ambientais a fim diagnosticar possíveis entraves que possam ser superados para a promoção do desenvolvimento rural sustentável.

Silva e Vieira em 2014, selecionaram 28 indicadores extraídos de um diagnóstico socioambiental efetuado pelo Instituo Nacional de Colonização e Reforma Agrária -INCRA e testou a ferramenta conhecida como Barometro da Sustentabilidade em 12 assentamentos localizados no Pará, a fim de analisar o nível de sustentabilidade destes. $\mathrm{O}$ autor identificou que os principais passos na análise da sustentabilidade 
dos assentamentos são a identificação dos temas, o estabelecimento dos indicadores, a definição dos limites dos indicadores e a avaliação dos mesmos na construção do índice de sustentabilidade e concluiu que em relação a dimensão ambiental a maioria dos assentamentos classificaram-se como potencialmente insustentáveis.

Mais recentemente Ribeiro et al (2016), ao entenderem que os indicadores ambientais vêm se consolidando como ferramenta de subsídio às políticas públicas em assentamentos rurais, se propuseram através de um levantamento realizado nas bases de dados Scopus, Scielo e Portal de Periódicos CAPES, entre 2000 a 2014, e utilizando palavras-chave como indicadores ambientais e assentamentos rurais, a analisar indicadores e metodologias utilizadas pelos autores da área e a investigar laços de citação entre os mesmos.

É sensível a percepção de que indicadores demandam diferentes características para alcançarem suas finalidades e, no âmbito dos assentamentos rurais, constata-se que estes referem-se à dimensão social, econômica, institucional e incipientemente a ambiental no que diz respeito a avaliar os impactos causados pelos assentamentos. O objetivo deste texto então, foi caracterizar a dinâmica do desmatamento em assentamentos localizados no Território Portal da Amazônia, localizado no norte do estado do Mato Grosso.

\section{DESENVOLVIMENTO}

Indicadores são variáveis definidas para medir um conceito abstrato, relacionado a um significado social, econômico ou ambiental, com a intenção de orientar decisões sobre um determinado fenômeno de interesse. Permitem balizar o entendimento e o andamento das ações e são fundamentais para avaliar objetivos, metas e resultados propostos.

Existem muitas definições e justificativas para o uso de indicadores. Para Kayano e Caldas (2002, p. 02), os indicadores são a descrição por meio de números de um determinado aspecto da realidade, ou números que apresentam uma relação entre vários aspectos, já para Cannavó (1999), citado em Leporace, (1999, p.48) são uma construção conceitual que utiliza fenômenos ou comportamentos observáveis, os quais podem ser postos em evidencia, aprendidos indiretamente mediante simbologias, medidas padronizadas singulares ou compostas, que dá ausência, presença ou intensidade de tais fenômenos ou comportamentos, deduz a dimensão de um conceito (CANNAVÓ, 1999, p.7 apud LEPORACE, 1999).

Como a sua utilização torna possível acompanhar e caracterizar as diferentes dimensões em seus vários espaços, sua aplicabilidade vem crescendo em diversas áreas de conhecimento entre as quais estão as áreas ambientais e agrárias. Assim, 
Ramos (1997) coloca que "com a necessidade em se simplificar objetos de estudo" surge a necessidade de se aplicar indicadores capazes de "representar distintos constituintes de um sistema e que ainda sejam relevantes para tal".

Os indicadores são classificados em quatro dimensões: a dimensão social: desdobrada em população, trabalho e rendimento, saúde, educação, segurança social e habitação, a dimensão econômica onde analisam-se índices relacionados a quadro econômico, energia e transportes, a dimensão institucional, que busca estudar temas relacionados ao quadro e a capacidade institucional do objeto de estudo e finalmente a dimensão ambiental que diz respeito ao uso dos recursos naturais e a degradação e se desdobra em temas relativos a terra, agua doce, biodiversidade e saneamento.

Corroborando então, com as de definições de McQueen e Noak (1988) que tratam um indicador como "uma medida que resume informações relevantes de um fenômeno particular", de Holling (1978) de que um indicador é "uma medida do comportamento do sistema, em termos de atributos expressivos e perceptíveis" e da OCDE (1993), Cooperação e Desenvolvimento Econômico de que um indicador "deve ser entendido como um parâmetro -ou valor derivado de parâmetros -que aponta e fornece informações sobre o estado de um fenômeno com uma extensão significativa" (OECD, 1993) e, sendo os mais desejáveis, aqueles que resumam ou simplifiquem as informações relevantes, façam com que certos fenômenos que ocorrem na realidade se tornem mais aparentes (GALLOPIN, 1996).

\section{Metodologia}

O recorte espacial - Território Portal da Amazônia (TPA) ${ }^{1}$ - abrange uma área de $111.167,50 \mathrm{Km}^{2}$, área de fronteira agrícola onde a discussão entre preservação ambiental e abertura de novas áreas para produção agropecuária é marcante. É composto por 16 municípios: Alta Floresta, Apiacás, Carlinda, Colíder, Guarantã do Norte, Marcelândia, Matupá, Nova Bandeirantes, Nova Canaã do Norte, Nova Guarita, Nova Monte verde, Novo Mundo, Paranaíta, Peixoto de Azevedo, Terra Nova do Norte e Nova Santa Helena (SIT/MDA, 2010) e trata-se de uma região localizada em pleno arco do desmatamento da floresta amazônica, na qual os conflitos socioambientais ocasionados pelo avanço da fronteira agrícola estão ainda muito presentes.

Optou-se pela realização de uma pesquisa exploratória, muito utilizada para

\footnotetext{
${ }^{1}$ Um espaço físico, geograficamente definido, geralmente contínuo, compreendendo a cidade e o campo, caracterizado por critérios multidimensionais - tais como o ambiente, a economia, a sociedade, a cultura, a política e as instituições - e uma população com grupos sociais relativamente distintos, que se relacionam interna e externamente por meio de processos específicos, onde se pode distinguir um ou mais elementos que indicam identidade e coesão social, cultural e territorial. (SECRETARIA DO DESENVOLVIMENTO TERRITORIAL).
} 
realizar um estudo preliminar do principal objetivo da pesquisa que será realizada, ou seja, familiarizar-se com o fenômeno que está sendo investigado, de modo que uma pesquisa subsequente possa ser concebida com uma maior compreensão e precisão. Para a coleta dos dados trabalhou-se com dados disponibilizados pelo Instituto Nacional de Reforma Agrária para obter a caracterização dos assentamentos (tamanho e número de famílias assentadas), bem como indicadores (para caracterizar o desmatamento) disponibilizados por:

- Instituto Brasileiro de Geografia e Estatística: Neste acesso, foi possível obtenção de dados sobre o crescimento populacional (entre os anos de 2008 a 2016) , da evolução da área plantada com soja das cidades que compõem objeto de estudo (2000 a 2015) e também da evolução do efetivo bovino nos últimos 15 anos na região estudada.

- Imazon: Acesso (através de dados gerados pelo SAD) a números relativos ao desmatamento no território entre 2014 e 2016.

- Inpe: Acesso aos focos de queimada entre 2014 e 2016.

\section{Resultados}

O Gráfico 1 ilustra a evolução do desmatamento no Mato Grosso no período de 2000 a 2015 e permite visualizar o continuo crescimento do desmatamento no estado, fenômeno acompanhado pelo TPA. As taxas mais intensas são registradas até o ano de 2005 quando o processo se estabiliza em taxas menos acentuadas.

A dinâmica do desmatamento na região do estudo é apresentada nas Figuras 01 e 02 abaixo. No primeiro mapa visualiza-se o desmatamento até o ano 2000 e na figura seguinte, o desmatamento acumulado até o ano de 2015. A evolução dos dados permite observar que o desmatamento possui crescimento em direção a região norte e noroeste do estado.

Os assentamentos de reforma agrária têm entrado de forma efetiva no debate sobre o desmatamento da Amazônia nos últimos anos (IMAZON, 2016). Entretanto, esse processo de criminalização ambiental dos assentamentos tem acontecido sem uma análise mais profunda da dinâmica do desmatamento dentro dos mesmos, sem levar em consideração outros aspectos além daqueles referentes à proporção da área desmatada e o percentual de contribuição anual para a perda de florestas (2016, p. 15) na região de estudo.

Existem no Brasil 9.128 mil assentamentos de reforma agrária, com 956.543 famílias assentadas pelo Instituto Nacional de Colonização e Reforma Agrária (INCRA). No Mato Grosso, são aproximadamente 549 assentamentos e cerca de 80 mil famílias assentadas. 
Gráfico 1 - Evolução do desmatamento no MT e Amazônia Legal entre 2000 e 2015.

$$
\begin{aligned}
& \text { Evolução do desmatamento no MT e Amazônia } \\
& \text { Legal (2000-2015) }\left(\mathrm{Km}^{2}\right)
\end{aligned}
$$

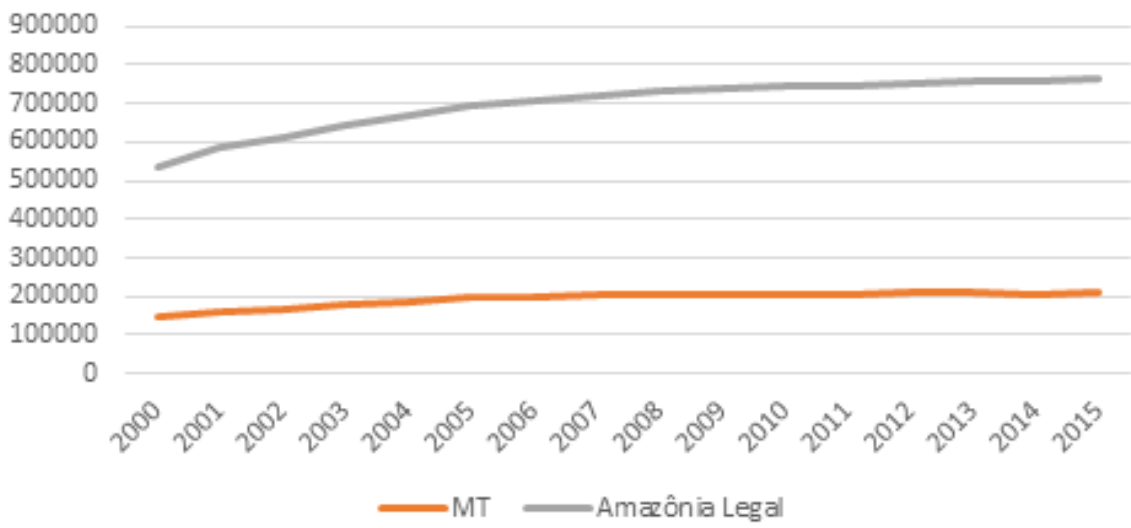

Fonte: www.dpi.inpe.br/prodesdigital/prodes.php.

Figura 01- Desmate até 2000 no TPA.

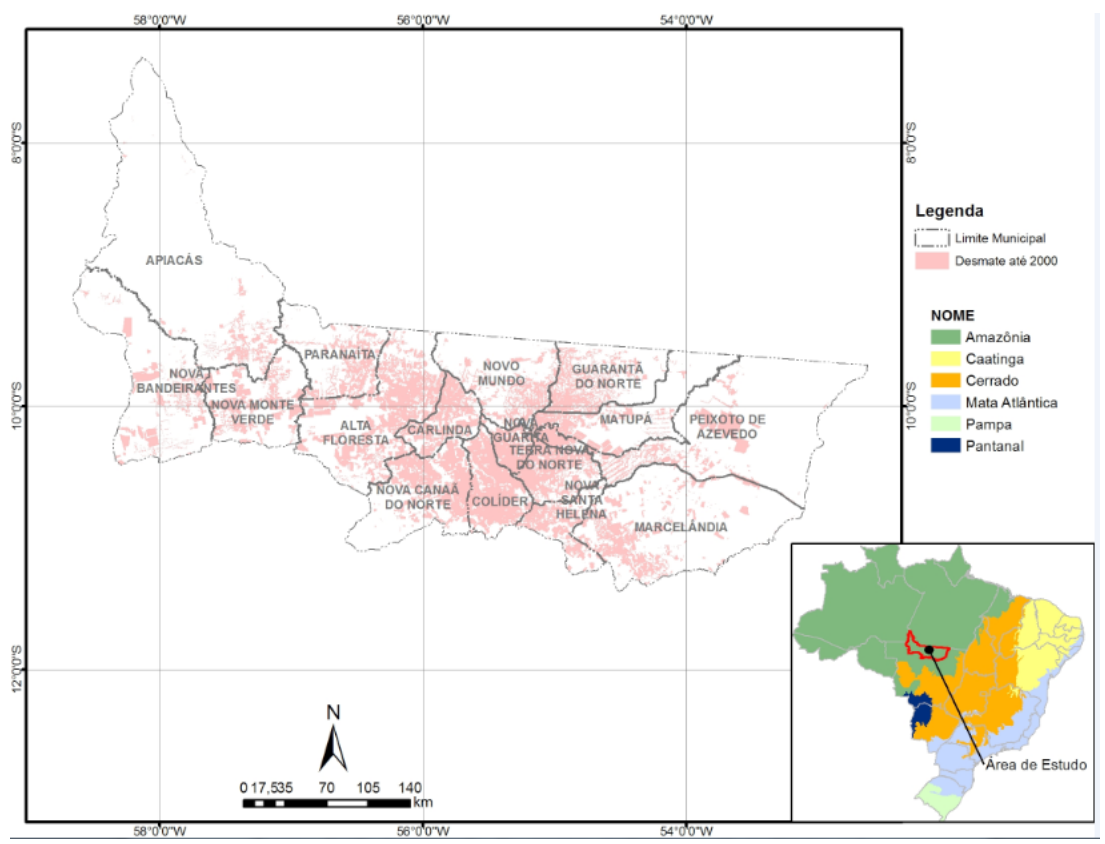

Fonte: www.dpi.inpe.br/prodesdigital/prodes.php. 
Figura 02 - Desmate até 2015 no TPA.

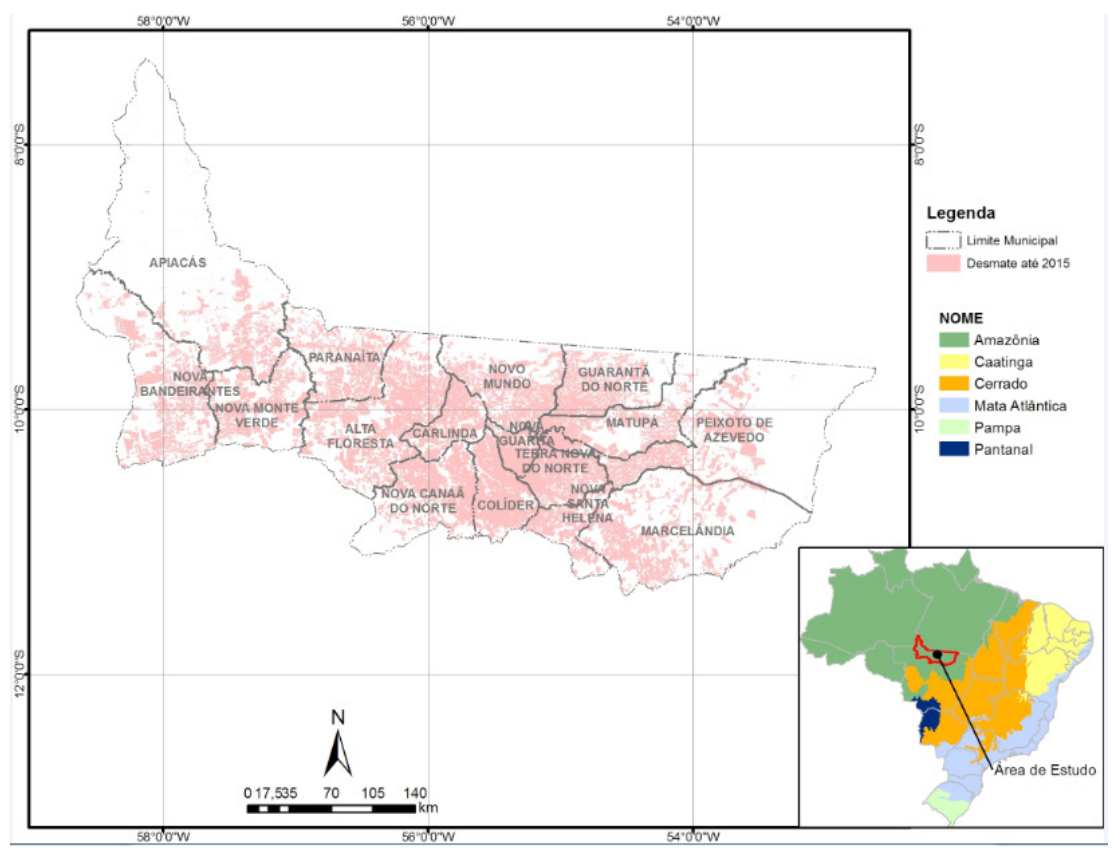

Fonte: www.dpi.inpe.br/prodesdigital/prodes.php.

Considerando especificamente o objeto de estudo, o Portal da Amazônia possui 76 Projetos de Assentamento convencionais (PAs), o que corresponde a mais de $13 \%$ dos projetos do estado. Estes projetos ocupam cerca de $26 \%$ da área total destinada a reforma agrária dentro do Mato Grosso, sendo que foram assentadas mais de 19.400 famílias na região (cerca de $24 \%$ do total de assentados do estado). O quadro abaixo buscou fazer um retrato do número de assentamentos no Território, bem como o número de famílias assentadas e da área destinada (em hectares) a sua ocupação.

No estado do MT 96\% dos assentamentos são convencionais e apenas 4\% diferenciados ${ }^{2}$ (como PDS, PAF, PAE). No Portal da Amazônia, os PAs (projetos de assentamentos convencionais) são quase a totalidade e suas dinâmicas migram da lógica de colonização do território para uma lógica de apoio à produção no campo e de redistribuição de terras. Os PAs reinaram quase que absolutos até 1988, quando a categoria de assentamento ambientalmente diferenciado, inaugurada pela modalidade PAE, foi criada, quebrando o paradigma produtivo de base não florestal praticado na maioria dos PAs, e acolhendo uma lógica

${ }^{2}$ Projeto de Desenvolvimento Sustentável (PDS), Projetos de Assentamentos Florestais (PAF) e Projetos de Assentamentos Agroextrativistas (PAE). 
produtiva que valorizava a floresta em pé (IMAZON, 2016). Entretanto, apenas dois PDS (Projetos de Desenvolvimento Sustentável) existem no Portal.

Tabela 01 - Assentamentos - Informações Gerais.

\begin{tabular}{lll}
\hline MUNICÍPIO & FAMÍLIAS ASSENTADAS & ÁREA PA \\
ALTA FLORESTA & 1603 & 92765,9497 \\
APIACÁS & 273 & 14843,1715 \\
CARLINDA & 115 & 5359,4885 \\
COLÍDER & 1867 & 68071,6024 \\
GUARANTÃ DO NORTE & 2455 & 155664,0094 \\
MARCELÂNDIA & 359 & 11749,1643 \\
MATUPÁ & 1294 & 90472,8988 \\
NOVA BANDEIRANTES & 1200 & 106918,6469 \\
NOVA CANAÃ DO NORTE & 983 & 63733,0507 \\
NOVA GUARITA & 491 & 27092,472 \\
NOVA MONTE VERDE & 123 & 8098,645 \\
NOVO MUNDO & 2973 & 496504,1625 \\
PARANAÍTA & 818 & 35092,8204 \\
PEIXOTO DE AZEVEDO & 2404 & 196365,9089 \\
TERRA NOVA DO NORTE & 2515 & 279527,9871 \\
Total Geral & 19473 & 1652259,978
\end{tabular}

Fonte: INSTITUTO NACIONAL DE COLONIZAÇÃO E REFORMAAGRÁRIA, 2016.

Quatro municípios do TPA (Guarantã do Norte, Novo Mundo, Peixoto de Azevedo e Terra Nova do Norte) respondem por $68 \%$ das áreas de assentamento no Território e 53\% das famílias instaladas nos assentamentos.

Os assentamentos da reforma agrária têm despontado como um dos principais focos de desmatamento na Amazônia nos últimos anos. Este fato tem sido ressaltado principalmente pela mudança no perfil do tamanho do desmatamento na região, de grande para pequenos polígonos (ALENCAR et al., 2013 apud IMAZON, 2016, p. 41). Padrão este que tem se repetido dentro dos assentamentos, e que tem impactado as suas taxas anuais de conversão florestal.

Dados retirados do PRODES/INPE e Projeto Radis-UnB demonstram que os assentamentos do TPA contribuem com taxas de até $50 \%$ do desmatamento municipal. A Tabela 02 ilustra esses dados.

Ressalta-se que o Projeto Radis-UnB em sua fase atual não atua em todos os 
municípios do TPA e, portanto, as informações são restritas aos dez municípios de atuação do projeto. Ainda assim, é possível identificar aspectos relevantes da dinâmica e correlação entre assentamentos e desmatamento na região.

O município de Guarantã do Norte, com área de 471.300 hectares é o mais destacado neste processo. Cerca de $46 \%$ de sua área está destinada a assentamentos de reforma agrária e foi identificado pelas imagens de satélite analisadas pelo Projeto Radis-UnB que 122.546,44 hectares foram desmatados em assentamentos até 2015, correspondendo a 50\% do desmatamento total (243.190 hectares) acumulado no município.

No caso de Matupá, 33\% do desmatamento municipal ocorre em áreas de assentamentos e em Peixoto de Azevedo esta taxa é de 30\%. Já os assentamentos do município de Novo Mundo respondem por $27 \%$ do desmatamento total da cidade até o ano de 2015.

Tabela 02 - Contribuição dos assentamentos ao desmatamento em municípios do TPA.

\begin{tabular}{|c|c|c|c|c|c|c|c|c|}
\hline Municipios & Área Assentamentos ${ }^{1}$ & $\begin{array}{c}\text { Área } \\
\text { município }^{2}\end{array}$ & $\begin{array}{c}\text { Desmate até } \\
2008^{1}\end{array}$ & $\begin{array}{c}\text { Desmate após } \\
2008^{1}\end{array}$ & \begin{tabular}{|} 
desmate total \\
nos \\
assentamentos
\end{tabular} & $\begin{array}{c}\text { Desmate até } 2015 \\
\text { município }^{2}\end{array}$ & $\begin{array}{c}\text { área } \\
\text { assent/muncípio }\end{array}$ & $\begin{array}{c}\text { desmate } \\
\text { assent/desmate } \\
\text { municipio }\end{array}$ \\
\hline & \multicolumn{6}{|c|}{ (hectares) } & $\%$ & $\%$ \\
\hline CARLINDA & $5.383,31$ & $241.700,00$ & $2.334,03$ & 494,39 & $2.828,42$ & $172.400,00$ & $2 \%$ & $2 \%$ \\
\hline GUARANTA DO NORTE & $215.597,10$ & $471.300,00$ & $118.074,31$ & $4.472,13$ & $122.546,44$ & $243.190,00$ & $46 \%$ & $50 \%$ \\
\hline MARCELANDIA & $11.814,94$ & $1.229 .500,00$ & $10.703,10$ & 194,03 & $10.897,13$ & $357.260,00$ & $1 \%$ & $3 \%$ \\
\hline MATUPA & $91.388,60$ & $515.100,00$ & $53.854,99$ & $11.452,18$ & $65.307,17$ & $198.250,00$ & $18 \%$ & $33 \%$ \\
\hline NOVA GUARITA & $24.350,75$ & $108.700,00$ & $15.920,45$ & $1.542,04$ & $17.462,49$ & $93.240,00$ & $22 \%$ & $19 \%$ \\
\hline NOVA MONTE VERDE & $3.044,97$ & $527.700,00$ & $2.336,35$ & 15,46 & $2.351,81$ & $237.500,00$ & $1 \%$ & $1 \%$ \\
\hline NOVO MUNDO & $91.717,47$ & $580.300,00$ & $62.233,85$ & $6.543,77$ & $68.777,62$ & $254.690,00$ & $16 \%$ & $27 \%$ \\
\hline PEIXOTO DE AZEVEDO & $142.917,81$ & $1.440 .000,00$ & $95.156,66$ & $9.162,50$ & $104.319,16$ & $352.170,00$ & $10 \%$ & $30 \%$ \\
\hline TERRA NOVA DO NORTE & $34.930,02$ & $255.100,00$ & $31.230,37$ & $1.172,47$ & $32.402,84$ & $214.160,00$ & $14 \%$ & $15 \%$ \\
\hline TOTAL & $621.144,97$ & $5.369 .400,00$ & $391.844,11$ & $35.048,97$ & $426.893,08$ & $2.122 .860,00$ & & \\
\hline Fontes: & ${ }^{1}$ Projeto Radis & ${ }^{2}$ PRODES/INPE & ${ }^{1}$ Projeto Radis & ${ }^{1}$ Projeto Radis & jeto Radis & & & \\
\hline
\end{tabular}

Fonte: Prodes/INPE e Projeto RADIS, 2016.

Para Leite et al (2004, p.45), os impactos dos assentamentos são representados pelas "mudanças que ocorrem na relação do assentamento com o seu entorno" e podem ser consolidados em oito eixos temáticos: poder local, participação política e políticas públicas, organização social, configuração produtiva, meio ambiente e ordenamento territorial, demografia, condições de vida e percepção dos próprios sujeitos do processo. Conforme Herédia et al (2003), essas mudanças ocorrem principalmente em função de possibilitar a ampliação de demandas de infraestrutura, como estradas, escolas, postos de saúde, energia elétrica, crédito, etc., derivadas da pressão sobre os poderes públicos locais e estaduais responsáveis pela prestação de serviços.

Como principais influenciadores diretos de desmatamento dentro dos assentamentos (IMAZON, 2016), pode-se colocar a pecuária extensiva e a extração 
madeireira ilegal, seguidas pela prática de agricultura de corte e queima, resultando em derrubada da cobertura vegetal nativa. Constata-se que, entre outros pontos, donos de terras se desfazem de suas propriedades, entregando-as a comerciantes locais, madeireiros etc., que nelas empregam suas próprias normas de exploração econômica.

A pecuária é uma atividade presente na grande maioria dos assentamentos, pois é uma atividade de baixo custo, fácil implantação e mercado seguro (WALKER, MORAN, ANSELIN, 2000). O Gráfico 02, apresenta como se deu a evolução do rebanho bovino nos últimos quinze anos, tanto no estado do Mato Grosso, como no Território Portal da Amazônia.

A criação de animais de grande porte é a atividade que mais cresceu no TPA nos últimos 15 anos. Enquanto no Brasil o crescimento do rebanho foi da ordem de 27\%, no MT foi de 55\% e no Portal da Amazônia, este crescimento foi de $98 \%$. A presença dos principais frigoríficos na região (Alta Floresta, Matupá e Nova Canaã do Norte) contribuem para este crescimento.

Já a exploração ilegal de madeira, mesmo gerando renda e infraestrutura de acesso para as famílias, é realizada sem plano de manejo e planejamento adequado. A agricultura convencional (de corte e queima), apesar de ser uma estratégia de manejo tradicional do uso da terra, também demanda a incorporação anual de novas áreas de floresta para garantir uma melhor produtividade nos ciclos de produção agrícola, acarretando em desmatamento (IMAZON, 2016; projeto RADIS, 2016).

Importante colocar que no TPA o cultivo de soja também pode ser considerado como um propiciador de conversão florestal em alguns assentamentos, merecendo importância no contexto geral do desmatamento (Gráfico 03).

Observa-se que nos municípios selecionados e apresentados nos Gráficos 04 e 05 o efetivo bovino diminui, enquanto a área plantada com soja cresce significativamente.

Este fenômeno pode ser explicado pela conversão de áreas de pastagens em áreas de cultivo de soja, inclusive em assentamentos. A rentabilidade econômica da soja e o nível tecnológico da assistência técnica privada explicam a possível substituição de pastagens por essa cultura.

Vale destacar que os municípios de Marcelândia, Alta Floresta e Peixoto de Azevedo são listados como prioritários ${ }^{3}$ no combate ao desmatamento pelo Ministério do Meio Ambiente. 
Gráfico 02 - Evolução do rebanho bovino 2000 - 2015.

Evolução do rebanho bovino - Mato Grosso e TPA (20002015)

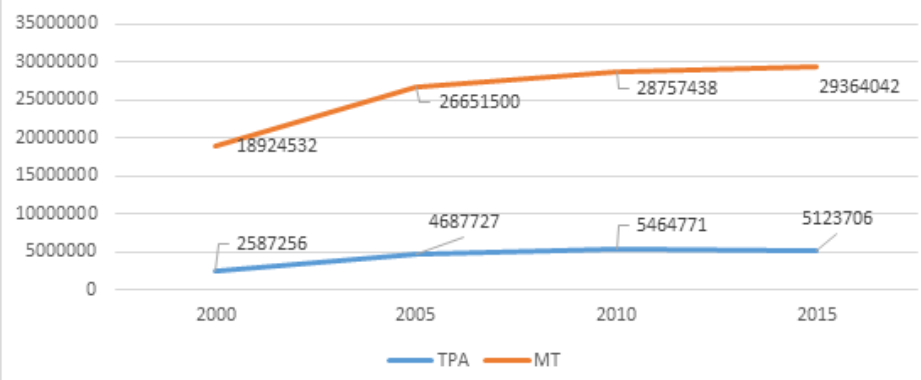

Gráfico 03 - Evolução da área plantada com soja (2000 - 2015).

Área Plantada de Soja no TPA (2000-2015) (ha)

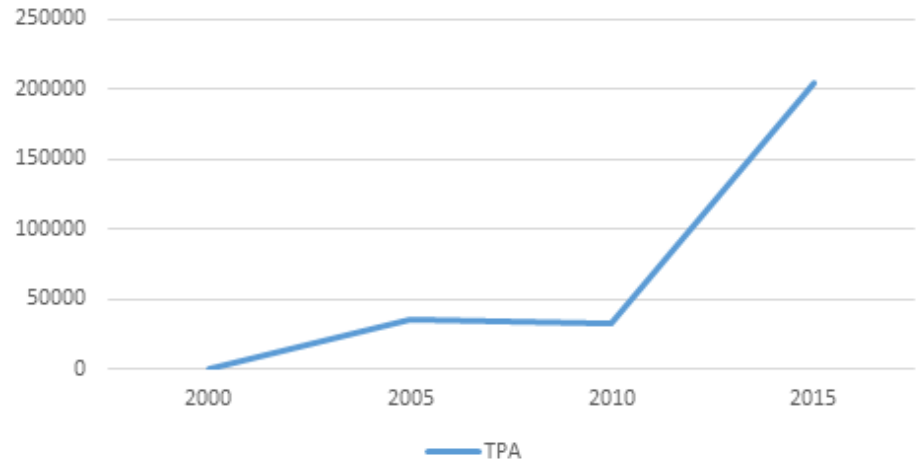

Gráfico 04 - Evolução de rebanho em municípios selecionados (2000 - 2015).

Evolução de rebanho - municipios selecionados

$$
\text { (2000-2015) }
$$

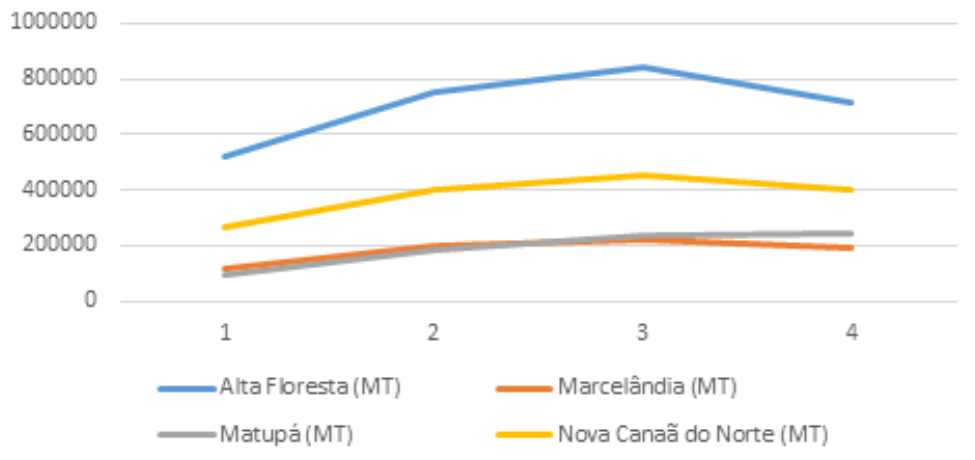

Fonte: IBGE - elaborado pelos autores. 
Gráfico 05 - Evolução de área plantada com soja em municípios selecionados $(2000-2015)$.

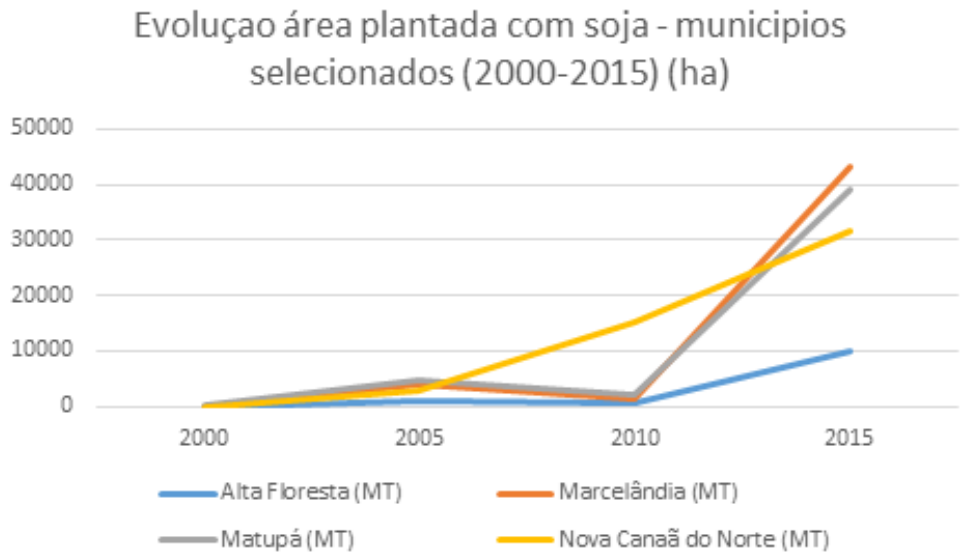

Fonte: IBGE - elaborado pelos autores.

\section{CONSIDERAÇÕES}

Dentre os modelos de assentamentos existentes, os projetos de assentamento convencionais (PA's) são a modalidade de assentamento de reforma agrária que mais converteu suas florestas em outros usos da terra, sendo que neste estudo, os que respondem por parcelas significativas de desmatamento estão nos municípios de Guarantã do Norte, Novo Mundo e Peixoto de Azevedo.

$\mathrm{Na}$ prática, está bem evidente a dinâmica de desmatamento ocasionado pela ocupação para pastagens, criação de bovinos seguido de culturas anuais (soja) em regiões selecionadas e migração para novas áreas para reiniciar o ciclo apresentado. A pecuária é uma atividade presente na grande maioria dos assentamentos, pois é uma atividade de baixo custo, fácil implantação e mercado seguro, porém, demanda a incorporação permanente de novas áreas, causando desmatamento. Já a soja é responsável pelo desmatamento em assentamentos cujas cidades estão ao longo da BR153 e, além de deslocar a pecuária para novas áreas, é caracterizada pelo intenso uso de agrotóxicos e por alimentar intensos conflitos fundiários.

Vale lembrar que esses vetores são também potencializados pela dificuldade de acesso a políticas públicas, principalmente aquelas ligadas à Assistência Técnica e Extensão Rural qualificada e adaptada às condições regionais, resultando num círculo vicioso - baixa produtividade dos assentamentos - incremento de novas áreas de floresta ao modelo produtivo e consequente aumento do desmatamento.

Entender a dinâmica do desmatamento nos assentamentos localizados no 
Território Portal da Amazônia é essencial para que se busque implementar talvez, um modelo mais sustentável - capaz de conciliar a conservação da floresta e ainda melhorar a condição de vida dos assentados - bem como reduzir conflitos e pobreza rural.

\section{REFERÊNCIAS}

ALCORINTE, M. G., et al. Avaliação ambiental de assentamentos rurais: uma abordagem comparativa multivariada. Retratos de assentamentos, v.16, n.2, 2013.

GALLOPIN, G. C. Environmental and sustainability indicators and the concept of situational indicators. A system approach. Environmental Modelling \& Assessment, v.1, p.101-117, 1996.

GUIMARÃES, R.P.; FEICHAS, S.A.Q. Desafios na construção de indicadores de sustentabilidade. Ambiente \& Sociedade, v.12, n.2, p.307-323, 2009.

HOLLING, C. S. (Ed.) Adaptive environmental assessment and management. Chichester: John Wiley \& Sons Ltd., 1978.

IBGE - Instituto Brasileiro de Geografia e estatística. Disponível em: www. cidades.ibge.gov.br/xtras/home.php?lang=_EN. Acesso em: 02/01/2019.

IMAZON - Desmatamento nos Assentamentos da Amazônia: histórico, tendências e oportunidades. Instituto de pesquisa ambiental da Amazônia. IPAM, Brasília, DF, 2016. 93p.

INCRA - Instituto Nacional de Colonização e Reforma Agrária. Assentamentos. Disponível em: <http://www.incra.gov.br/assentamento>. Acesso em: $17 / 11 / 2018$.

INPE - Instituto Nacional de pesquisas espaciais. Projeto prodes: monitoramento da floresta amazônica brasileira por satélite. Disponível em: http:// www.obt.inpe.br/prodes/index.php. Acesso em 02/01/2019.

JANNUZZI, P. M. Indicadores sociais no Brasil: conceitos, fonte de dados e aplicações. Campinas: Alínea, 2001.

KAYANO, J.; CALDAS, E. L. Indicadores para o diálogo. In: CACCIA-BAVA, S. (coord.) Novos contornos da gestão local: conceitos em construção. São Pau- 
lo: Polis, 2002.

LEITE JÚNIOR, C. B. et al. Indicadores social-econômico e ambiental em Retratos de assentamentos, v.16, n.2, 2013125 assentamentos de reforma agrária no cerrado goiano. Campo-território: revista de geografia agrária, v. 8, n. 16, p. 342-378, Ago. 2013.

LEPORACE, M. Indicadores sociopopulacionais: conceito, construção e utilização (notas introdutórias), texto base do II Curso de Construção de indicadores sociopopulacionais para o planejamento. Brasília: CODEPLAN, 1999.

OECD. Organization for Economic Cooperation and Development: core set of indicators for environmental performance reviews; a synthesis report by the group on the State of the environment. Paris, 1993.

RAMOS, T. B. Sistemas de indicadores e índices ambientais. Congresso nacional dos engenheiros do ambiente, 4, 1997,

RIBEIRO, M. L. et al. Indicadores ambientais em assentamentos rurais: uma análise citacional. Retratos de assentamentos, v.19, n.2, 2016.

SILVA, V. C. S.; VIEIRA, I. C. G. Barômetro da Sustentabilidade aplicado a assentamentos rurais do leste do Estado do Pará, Brasil. Sistema eletrônico de revistas, SER/UFPR. Vol. 36, abril 2016, DOI: 10.5380/dma.v36i0.39957. 